\title{
Drive level and preference between two incentives'
}

Gordon H. Bower

STANFORD UNIVERSITY

\begin{abstract}
Spence's theory predicts that preferential choice between two magnitudes of reward will be independent of drive level if the conditions insure equal experience with the alternative choice responses. This prediction was tested by training rats in a $\mathrm{T}$ maze to choose between four and three pellets of food reward, half the Ss under high and half under low degrees of food deprivation. The groups attained the same degree of asymptotic preference independent of drive level, thus confirming the theory's prediction.
\end{abstract}

\section{Problem}

The problem was to determine whether drive level influences preferential choice between two magnitudes of reward under conditions which insure equated experience with the alternatives. Adopting Spence's theory (1956), the habit strength $(\mathrm{H})$ of a response is a function of its number of occurrences to a stimulus whereas reward factors determine the incentive motivation $(\mathrm{K})$ for that response. Using the subscripts $\mathrm{L}$ and $\mathrm{S}$ to represent the larger and smaller reward sides of the $\mathrm{T}$ maze, the relevant equations for reaction potential $(\mathrm{E})$ from Spence's theory are as follows:

$$
\begin{gathered}
\mathrm{E}_{\mathrm{L}}=\mathrm{H}_{\mathrm{L}}\left(\mathrm{K}_{\mathrm{L}}+\mathrm{D}\right) \\
\mathrm{E}_{\mathrm{S}}=\mathrm{H}_{\mathrm{S}}\left(\mathrm{K}_{\mathrm{S}}+\mathrm{D}\right) \\
\mathrm{E}_{\mathrm{L}}-\mathrm{E}_{\mathrm{S}}=\mathrm{D}\left(\mathrm{H}_{\mathrm{L}}-\mathrm{H}_{\mathrm{S}}\right)+\mathrm{H}_{\mathrm{L}} \mathrm{K}_{\mathrm{L}}-\mathrm{H}_{\mathrm{S}} \mathrm{K}_{\mathrm{S}}
\end{gathered}
$$

In the theory, $\mathrm{H}$ and $\mathrm{K}$ are learned variables that increase with trials, the asymptote of the latter varying with the amount of reward. Equation 1 exhibits Spence's assumption that drive and incentive motivation combine additively in determining response tendency. The percentage choice of the larger-reward side in the $\mathrm{T}$ maze is an increasing (normal integral) function of the difference given in Eq. 2.

In the following experiment, the number of runs to the $\mathrm{L}$ and $\mathrm{S}$ sides were equated by interspersing forced runs amongst free choice trials. The theory expects this procedure to equate habit strength to the two sides, or $\mathrm{H}_{\mathrm{L}}=\mathrm{H}_{\mathrm{S}}$. In this case, the difference in Eq. 2 reduces to $\mathrm{H}\left(\mathrm{K}_{\mathrm{L}}-\mathrm{K}_{\mathrm{S}}\right)$ which is not a function of drive level. Thus, the expectation is that asymptotic preference of $\mathrm{L}$ over $\mathrm{S}$ would be the same for high and low drive Ss. The two reward magnitudes (4 vs. 3 Noyes food pellets) were deliberately selected so that asymptotic preferences would be less than unity, thus affording a discriminating test.

\section{Method}

Sixteen male Wistar rats, 90 days old, served as Ss.
The 8 Ss assigned to the high-drive condition were fed $9 \mathrm{gms}$ daily of Purina lab checkers, whereas the $8 \mathrm{Ss}$ in the low-drive condition were fed 15 gms daily. Body weights over the last 20 days of the study ranged from 197-227 gms for the low-drive Ss, and from 140-163 gms for the high-drive Ss. The apparatus was a wooden enclosed $\mathrm{T}$ maze painted flat black throughout. The stem was $30 \times 4 \times 4$ in and each arm was $24 \times 4 \times 4$ in. Bottle caps secured to the floor at each arm-end served as foodcups. Guillotine doors partitioned a startbox and the two arms. Forcing was accomplished by lowering one of these doors to block the appropriate alley. Each $S$ received 4 Noyes food pellets ( $45 \mathrm{mgm}$ each) on one side of the maze and 3 pellets on the other side. Four Ss in each drive group had the 4 pellets on the right side of the maze, whereas the other Ss had it on the left side. Training totalled 22 days and 138 trials, half free and half forced choice. Days 1-5 were at 4 trials, days 6-14 at 6 trials, and days $15-22$ at 8 trials. Starting with a free choice trial, free and forced trials alternated, the forced response being to the side opposite that chosen on the preceding free choice trial. The average intertrial interval within a day's session was $12 \mathrm{~min}$.

\section{Results}

Average percentage choices of the 4-pellet side on the free choice trials of each day are shown in Fig. 1. During the initial 15 days, the low-drive Ss exhibit a somewhat greater preference than do the high-drive Ss. Average percentage choices over these initial 15 days

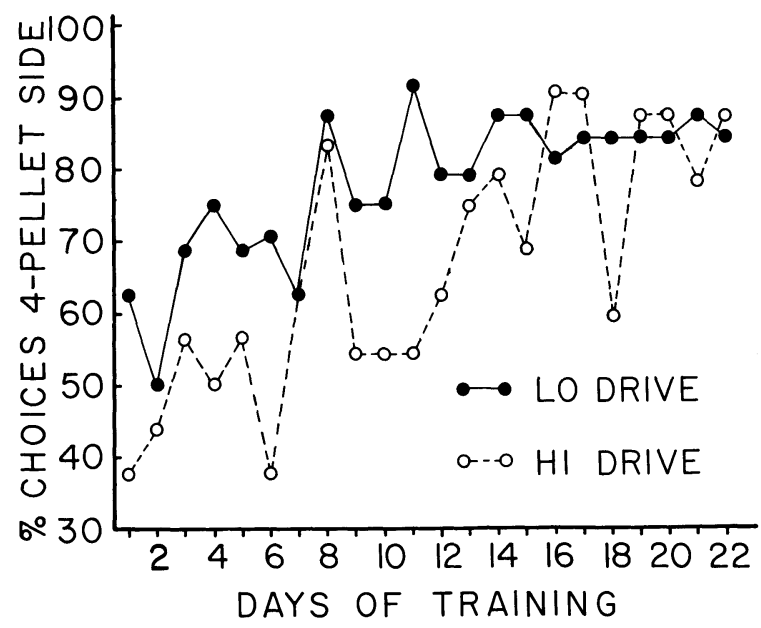

Fig. 1. Group average percentage choices of the larger reward side of the $\mathrm{T}$ maze, plotted for the free trials of each training day. 
were 76 and $61 \%$ for low- and high-drive Ss; these do not differ significantly $(t(14)=1.55)$. The two groups appear to arrive at the same asymptotic level of preferential choice. Over the last 7 days of training, percentage choices of the 4-pellet side were 84 and $83 \%$ for the low- and high-drive $\mathrm{Ss}$, respectively. One $\mathrm{S}$ in each group exhibited a preference for the 3-pellet side. Eliminating the deviant $\mathrm{S}$ from each group, the average asymptotic choices were 92 and $91 \%$ for the low- and high-drive Ss.

\section{Diseussion}

The theory's prediction about equal asymptotic preference was confirmed. Also the slight superiority of the low-drive Ss early in training is consistent too with the theory if the reaction threshold is taken into account as Spence has suggested (Spence, 1956, pp. 203-206, 237-242). This proposal makes choice percentage sensitive to the absolute E-values as well as the difference $E_{L}-E_{S}$. The relevant implication for this discussion is that, for a particular $E_{L}-E_{S}$ difference, preferential choice will be higher when the absolute E-values are low and near threshold. Such conditions would be expected for the low-drive Ss early in training. After extended practice when the habit and incentive variables have reached their respective asymptotes, the dispersion of E-values exceeds the threshold and preferential choice is a function only of the difference in E-values. On this theory then the expected pattern of results is approximately that obtained in the present experiment.

As always, a single experimental test of a theory which involves a number of assumptions (as the Spence theory does) derives its main power and theoretical leverage from data collected in previous experiments which have constrained the relevant alternatives. Foregoing those constraints, the present results of equal preference under high and low drive would be consistent with the following assumptions: (a) drive, incentive, and habit combine multiplicatively as Hull (1951) had supposed, and (b) choice percentages are calculated from Luce's (1959) axiom, viz., $P(L>S)=E_{L} / E_{S}+E_{L}$. Though consistent with the present result, the latter set of assumptions do not account for a range of facts from instrumental conditioning which purport to show that $\mathrm{K}$ and $\mathrm{D}$ should combine additively in the theory (e. g., Logan, 1960; Reynolds \& Pavlik, 1960; Brush et al., 1961).

\section{Referemees}

BRUSH, F. R., GOODRICH, K. P., TEGHTSOONIAN, R., \& EISMAN, E. H. Running speed as a function of deprivation condition and concentration of sucrose. Psychol. Rep., 1961, 9, 627-634.

HULL, C. L. Essentials of behavior. New Haven: Yale Univer. Press, 1951.

LUCE, R. D. Individual choice behavior. New York: Wiley, 1959.

LOGAN, F. A. Incentive. New Haven: Yale Univer. Press, 1960.

REYNOLDS, W. R., \& PAVLIK, W. B. Running speed as a function of deprivation period and reward magnitude. J. comp. physiol. Psychol., 1960, 53, 615-618.

SPENCE, K. W. Behavior theory and conditioning. New Haven: Yale Univer. Press, 1956.

\section{Note}

1. This research was supported by a grant, HD 00954 , from the National Institute of Child Health and Human Development. 